\title{
Noonan syndrome-like disorder with loose anagen hair
}

INSERM

\section{Source}

INSERM. (1999). Orphanet: an online rare disease and orphan drug data base. Noonan syndrome-like disorder with loose anagen hair. ORPHA:2701

Noonan-like syndrome with loose anagen hair (NS/LAH) is a Noonan-related syndrome, characterized by facial anomalies suggestive of Noonan syndrome (see this term); a distinctive hair anomaly described as loose anagen hair syndrome (see this term); frequent congenital heart defects; distinctive skin features with darkly pig mented skin, keratosis pilaris, eczema or occasional neonatal ichtyosis (see this term); and short stature, often associated with a GH deficiency and psychomotor delays. 